\title{
New development strategy of complex financial system engineering and risk management research
}

\author{
Qi Mingchun
}

\author{
(Department of Applied Mathematics and Economics, Sichuan Vocational and Technical College, \\ Suining, Sichuan, 629000)
}

Key words: complex; financial system engineering; risk management; measures

\begin{abstract}
There are many factors affecting risk management, one of the most important factors affecting risk management is the financial system engineering, How to promote the integration of the two aspects, and autonomous response to unexpected risks has become a major issue faced by many financial managers. This paper briefly introduces the characteristics of complex financial system, analyzes the main problems existing in the risk management of complex financial system engineering, and based on this, puts forward some concrete measures to deal with risk management.
\end{abstract}

\section{Introduction}

With the rapid development of the social economy in our country, the large-scale application of information technology has laid a solid foundation for the realization of globalization of financial system engineering to a certain extent, and has brought many new financial development. The development space of financial enterprises has also gone from domestic to the international, and the market development space also has a qualitative improvement. In order to control the risk factors at the lowest level and realize the maximization of economic benefits, we must proceed from the overall situation, effectively control the new concept and methods of financial development, and thus to build a more scientific preventive measures and risk management system.

\section{Analysis of the characteristics of complex financial system}

Complex financial system has a very significant characteristics, mainly reflected in complexity, periodicity and high risk these three aspects. Now its specific characteristics of the analysis are as follows:

(1) Complexity. The most prominent feature of complex system is high coupling degree, low transparency, large scale, dynamic, openness, and so on, one of the most fundamental characteristics is the non-linearity of each component and the adaptive ability of the system itself. The interaction between different components shows that things that are closely related to each other are not subject to unilateral interference, but to mutual interference and restriction, even the interdependence of each other, which is the fundamental characteristic of non-linearity. The most important feature of the complexity of financial system is the large scale of virtual capital, the multi-level internal level, the open system of dynamic change, and also include the important uncertain influence factors of the influence of human decision - making. The system itself is similar to the uncertain state of random change because of the non-linearity effects between different components, and because of the self-organization effect of the system itself, it also shows some stability and orderliness in the internal structure ${ }^{[1]}$.

(2) Periodicity.The most important evolution of the financial system is basically showing a very significant periodicity characteristics, usually accompanied by the rapid growth of the real economy, the emergence of the bubble economy, the inflation of credit and monetary value, the general increase in asset prices, the excessive appreciation of the expected development of the market, the rising real estate prices, the rising stock market trading index showing a bullish state. People began to sell assets, solid economic growth, cooling, deceleration and even showed a negative growth trend. However, with the intervention of economic disturbance, the economic bubble is turned into 
nothingness, the financial market suffers severe vibration, people began to sell assets, solid economic growth, cooling and even showed a negative growth trend. The periodicity changes of the financial system described above have been verified in many countries or regions, such as the collapse of the Japanese real estate bubble in 1991 after the unprecedented madness, and then fell into the lost 20 years, a setback. It was also in the 1990s, when the Taiwan stock market crash fell from its highest point of 12682 and eventually fell below the issue price until 2485, its decline was unprecedented in the history of Chinese stock market. At the same time, it should be noted that such periodicity changes are not simple repetitions, but represent a spiral way of propulsion. At present, in our financial system, the main risk exists in the banking system, and the hidden risk more than $90 \%$ is derived from the unhealthy credit ecology, the long - term overdue loan backlog is growing exponentially. Although in recent years, after several major economic crisis, our government has strengthened the prevention of the financial system, adopted some adjustment measures, the bank credit ecology has gradually improved, the government even take the direct purchase of bad assets of banks. However, by the institutional factors influence, China's banking industry financial system is still very imperfect, and there is still a big gap with developed international financial industry

(3) High risk. The high risk of the financial system itself is mainly the source of its own complexity and the medium stability. On the one hand, the instability of virtual capital will lead to drastic changes in price, at the same time the expansion of the financial market and the increase of types will make the complexity of the financial market more complexity. On the other hand, it is difficult for people to make accurate judgment on the market environment in the rapid change, which leads to the occurrence of decision - making error.

\section{The main problems in risk management of complex financial system engineering.}

\subsection{The internal control system is not perfect.}

Based on the current financial risk management process, the complete internal control system can provide strong support for the risk control of financial institutions. However, due to the serious problems in structural governance, the risk management of financial institutions in China is lack of good operating system and organizational system security. From the current actual situation, most of the state-owned banks and the financial sector did not do the real risk management system to independent operate. Whether in internal audit, credit risk control, or interest rate risk management is not equipped with independent of the ability, and management capacity is particularly inadequate.

\subsection{The management tool is not perfect.}

In some countries with very developed financial industry, the risk management work available is very rich, and there are a lot of innovation derived. Looking at the financial industry in China, because of the short development time in the financial system, in the current financial market environment, it is difficult to provide a variety of risk management tools for financial institutions and investors. The lack in this aspect of financial risk management has become an important performance of relatively lagging in China. The peripheral financial product market is an area where the international financial industry provides the most risk management tools for investors and financial institutions ${ }^{[2]}$. The rich and diverse financial instruments can promote the investors and financial institutions to better conduct risk assessment and prevention, especially the peripheral financial instruments is the most important tool to strengthen market risk management, which can promote the financial system to better bear and the configuration risk.

\subsection{The risk bearing subject is not clear.}

Regardless of the risk management approach, the risk should be taken as the main body, the corresponding rights, responsibilities and interests should be properly configured. In some developed countries, only the board of directors is responsible for the bank and management risk, at the same time, the bank's total funds are used for the bottom line of risk. The board of directors will assume relevant risk management decisions and establish a scientific risk control system through the bank. However, in the current situation of the banking industry in our country, a large number of financial institutions, especially state-owned commercial banks, often define the ultimate 
stakeholders of risk factors not clearly. The most important feature is that the results of risk management will lead to the national macroeconomic management anomalies pay attention to financial risk, but the micro level of risk management is very weak, lack of necessary management initiative and enthusiasm.

\section{The prevention measures to deal with risk management.}

\subsection{Perfecting the management system}

Clearly define the nature of financial institutions, establish the appropriate property rights system and organizational structure system with economic development. Promote the clarity of property rights, further improve the corporate governance structure model, establish an equal rights and responsibility management system, so that risk income can be compatible with the development of operating mechanism.

\subsection{Strengthening policy support}

The development of financial institutions must be given the necessary support at the policy level, rather than just financial support, and it need to be able to give appropriate policy incentives to enable complex financial systems to avoid all kinds of unintended risks ${ }^{[3]}$.

\subsection{Strengthening the management of the organization}

Use the financial supervision and internal control management to strengthen organizational management, promote the deepening of financial reform, promote the capital to achieve better adequacy ratio, to enhance the ability to resist risk. Strengthen internal control management to enable management risk to be effectively reduced ${ }^{[4]}$.

\section{Concluding remarks:}

In short, in the current era of rapid social and economic development in our country, the risk of financial system engineering is increasing, and to cope with the complex and variable financial risk, actively adapt to the market changes must strengthen the improvement and perfection of the financial management system, to achieve effective management of the complex financial system, promote the financial institutions to achieve more stable development, and lay a solid foundation for the international market.

\section{References}

[1] Shi Xiaonan. Research on the present situation and countermeasures of risk management of financial institutions in China [ j ]. Times finance( late ), 2014, ( 8 ).

[2] Fang Lichong, Li Meng. Analysis of internal risk contagion effect in financial system - based on the empirical analysis of Chinese bond market, stock market and foreign exchange market $[\mathrm{j}]$. Modern economic information, 2014, ( 19 ).

[3] Liu Chaoju. The impact of the expansion of credit business on the banking financial system [ $\mathrm{j}$ ]. Foreign investment in China ( first half month), 2013, ( 2 ).

[4] Dai Xin. Research on risk prevention and control strategy of financial system operation under the economic new normal [ $\mathrm{j}$ ]. Rural economy and science technology, 2016, 27 ( 12 ).

Brief introduction of the author: Qi Mingchun(1981- ), male, people from Suining Sichuan, lecturer, department of applied mathematics and economics, Sichuan vocational and technical college, master of finance. Main research directions: Finance and regional economy. 